\title{
Complex Relationships Involved in Music Making: Results Founded in Music Invention Laboratory Practices applied in Music Education
}

\author{
Luciano da Costa Nazario, José Augusto Mannis \\ UNICAMP, Brazil
}

\begin{abstract}
This research is funded by São Paulo Research Foundation (FAPESP) and presents evidences obtained through laboratory and experimental work aimed at new pedagogical alternatives in the context of music education. Analysis of creative music as a pedagogical process in music education usually lacks elements that, although not musical in nature, are important for enhancing development of musical creativity. In this context, we propose the use of a reference model for creative development, showing the first results of its application and an analysis that allows a glimpse into the complexity of music making. The methodology used for the collection and analysis of data is centered on Grounded Theory by Glaser and Strauss, enabling observation of pedagogical and creative activities from both musical and social points of view. From the results, it was possible to observe significant emerging categories on the history of individuals as the core of their musical learning experiences, conservatism and previous knowledge, and the capacity of invention and equilibration, which allowed us to see whether certain beliefs in actions that involve success or failure in music creation were in fact effective true or not.
\end{abstract}

\section{Introduction}

This reseach is part of the doctoral project entitled Development of musical invention practices through heuristic processes: the stimulation of creativity in collective learning environments, which aims (through a theoretical study involving cognitive sciences, analysis of heuristic processes and motivational phenomena) to formulate a proposal that prioritizes creative practices in music learning in the form of invention exercises, considering the complex relationship between all these aspects.

The research foresees, in its schedule, a series of laboratory activities to be held at Free School of Music at Unicamp (ELM), a part of the Integration Documentation and Cultural Diffusion Center of the State University of Campinas (UNICAMP-CIDDIC). The laboratory was attended by volunteer musicians, who were informed of the nature of the activities and signed a Free and Informed Consent agreement (TCLE) in order to participate in the research.

It is considered that the laboratory activities proposed to the participants are of an experimental nature, because they are not usually performed in traditional schools of music in Brazil. In the laboratory, for example, participants do not play by reading a score as in traditional methods of classical music, but develop a given musical idea; They neither have to assimilate theoretical models and restricted content to only then putting them into practice (prior knowledge of model generally applied in popular music learning), since, in this proposal, the content is built by participants from very simple basic principles, allowing them to complete easely and with resourcefulness so they will not have an overly dominant logical-deductive intellectual effort, what would probably block their free musical expression.

The challenge in this lab, as well as the main strands on education nowadays, is the stimulus to creativity caused in the student. In this sense, one of the laboratory 's goals is to get them to discover new possibilities, create spontaneously from musical knowledge they already acquired, the center of attention turns out to be mainly the encouragement of discovery. For that, we conducted certain activities not requiring prior knowledge (musical genres, scales, harmonic progression etc.) so that students play more intuitively on their performances, acting with more self-confidence and being able to realize how naturally creative they are. We start this study, therefore, from the premise that creativity (as well as thought, rationality, memory, etc.) is a natural cognitive operation of the human being.

During these activities (carried out between September and December, 2014) the aim was to combine musical expertise and aspects related to inventiveness (refering to musical creation, individual or collective, that has been heuristically built), by using alternative techniques and materials such as: the use of non-musical objects (sound bodies) for musical purposes; the use of one's own body and voice in creative activities; environmental darkening to stimulate the auditory perception, and 
other experimental creations, with or without the use of traditional instruments.

The activities were based on constructive proposals, making room for the expression and manifestation of each participant's subjectivity, and encouraging the emergence of their own ways of processing the acquired knowledge. Within this context, the participants worked actively in the construction of knowledge. Their experiences, proposals, and musical achievements were strongly considered and the activities were conducted according to the group's characteristics.

\section{Reference Model for Creative Development}

The pedagogical basis adopted to perform the activities is based on the reference model proposed by the authors of this research, which includes elements that enables certain cognitive processes to be examined and specified in order to make it possible to synthesize partial results during the process through inferences based on the results of the partial analysis of the collected data [1]. Figure 1 presents a pedagogical model in which the base is the content and the focus is the final evaluation. Exploration, assimilation, application and invention actions are predetermined activities defined and structured as a function of the basic content and the objective to be achieved in class.

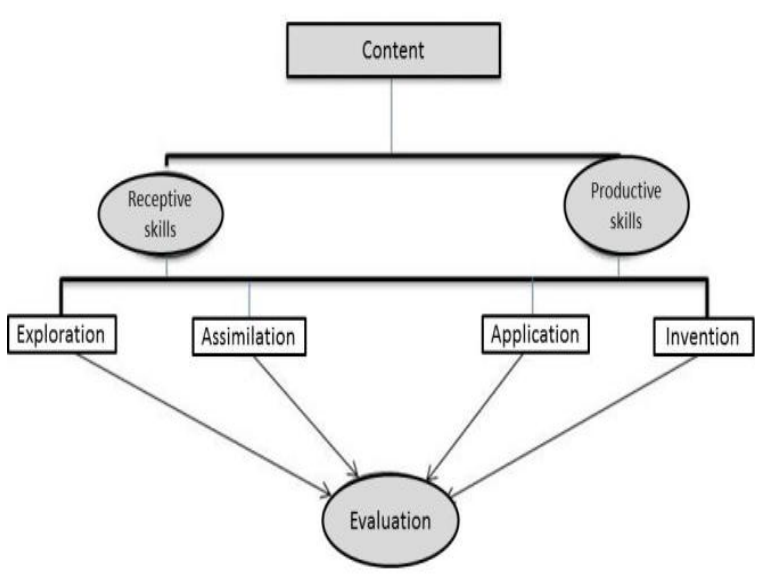

Figure 1: Reference model

These actions consist of: 1- Exploration: first contact with the content; sound discovery, curiosity; 2- Assimilation: repetition of actions in order to achieve a deeper understanding of the content inherent to these actions; 3- Application: systematization of assimilated content applied to a practical aim proposed in class. Application is characterized more as an exercise to locate the content within a given context; 4- Invention: Content synthesis employing artistic expressiveness tools already known and applied by the student, used to achieve an expressive goal. For such, a class situation is created, where the student is encouraged to explore the content inventively, establishing limits and, at same time, providing them with freedom for their creative act.

At the cognitive level, combinations of the actions in Figure 1 can occur simultaneously as it often happens during learning. The student can, in a single action, explore and assimilate his or her material. The same process can happen during inventions, where there occur, in rapid succession, almost simultaneously, exploration, assimilation and application of his or her choices in musical invention.

Receptive and productive skills arise from cognitive processes in which students acquire knowledge. In the receptive skill, sound stimuli are perceived, analyzed and synthesized (reconstructed mentally). In the productive skill, sound stimuli are constructed (simulated/performed) within a creative context. Receptive(a)/Productive(b) skills are interconnected and influence each other in the control over direction of attention, and in decisionmaking. In each one of them, the analysis of what is being immediately perceived $(a) / \operatorname{produced}(b)$ influences the direction of attention of one over the other.

To perceive, assimilate, and create musically from the representation of the acquired content is a complex cognitive process moved by volitional acts of artistic expression. It is observed in Figure 3, that in the phase of perception, in which we receive the information that will be processed, attention is driven and directed by volition. The investigation of what is being perceived occurs in the analysis process, in which rationality and abstraction, decomposition, comparison and association apparatus operate according to volitions, in approach, contrast and opposition:

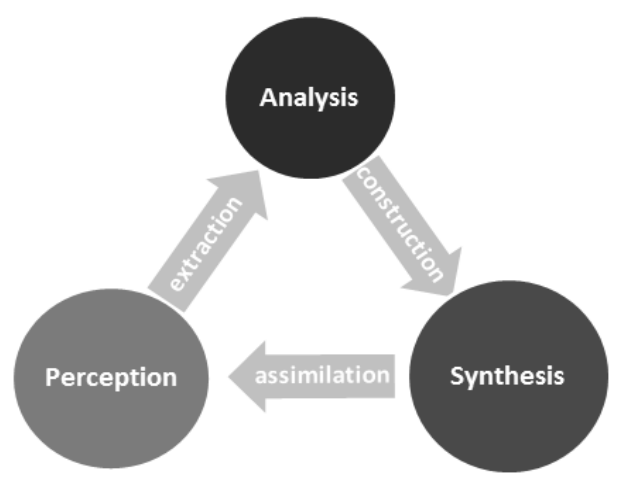

Figure 2: Cognitive cycle: sequenced actions [2] 
In possession of identified and located elements in the mapping of understanding, we move to the (re) construction of the analyzed object, therefore its reconstruction, in the form of a similar representation or a derived object, more or less unusual. The actual reconstruction of the object perceived or imagined materialized (simulated) in the synthesis, enhances the assimilation of content identified/designed in the object. The perception/analysis/synthesis processes are a triadic core constantly present in all the process, so that the perception activities as well as the analysis and synthesis, all the three of them occur fulfilling elementary cycle [2].

Looking up the whole process (see Figure 3), we can see how the cycle of perception to analysis to synthesis evolves from the first material to be processed, with different emphases in each situation, sometimes emphasis on perception, sometimes emphasis on analysis, sometimes emphasis on synthesis, always being completed and restarted again:

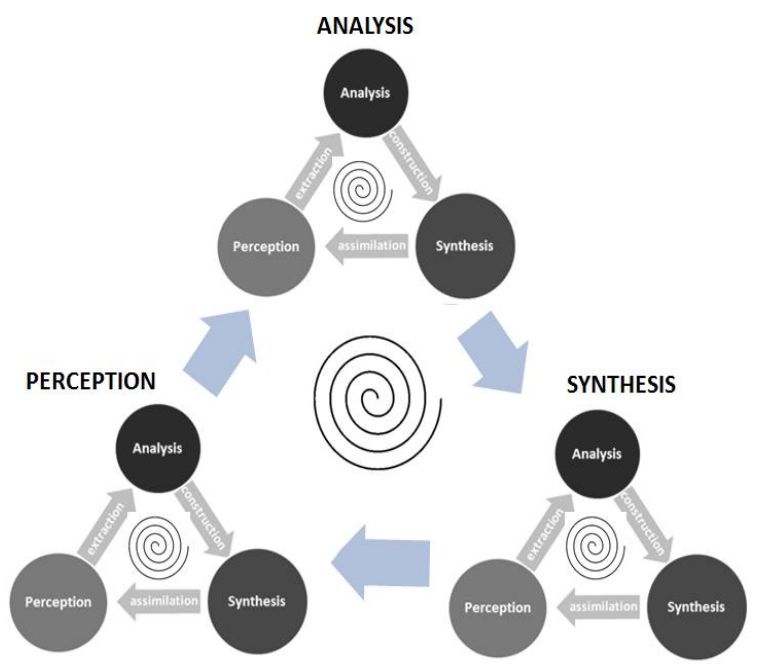

Figure 3: Cycle of Cognitive processes cycles in the creative process [2]

Cognitive limitations were also considered in this educational process. In this research, cognitive limitations are so interpreted as blocks inhibiting actions of performances. Therefore, it is observed, in practice, that the limitations related to these blocks usually occur when: (a) there are related to levels of knowledge, that is, certain mental connections have not yet been built, preventing the development of their receptive and productive skills on a higher level. For instance, a student who is beginning to mentally represent small melodic patterns has not yet built enough mental connections to enable him or her to design his or her creation on a higher level; (b) there are related to social and cultural context, that is, certain sound events, that due to social and cultural issues not yet assimilated, are not present in the listening grammar repertoire. For example, even experienced musicians may struggle to express themselves, play or create within genres and styles that are unfamiliar to or not common in their culture, especially if such genres make use of unknown musical materials.

In this context, during laboratory sessions, there was an attempt to avoid the requirement of practical exercises with sound materials or technical procedures that might be beyond the knowledge of the participants. The intention was to establish a balance between challenge and capability, stimulating them to achieve a state of concentration as they performed the activities.

Finally, evaluation, in Figure 1, includes the phenomena observed in exploration, assimilation, application, and invention activities, making it possible to identify what happens in the spheres of the recepctive and productive skills. The observation and study of these skills can reveal connections in the relationship between production and reproduction, that is, the interaction between perception and creative production throughout the whole period of implementation of the activities.

\section{Methods and Analyses}

The analysis tool is based on people, process, and product evaluation, through the study of audiovisual recordings, questionnaires and participants' reports. During the laboratory period, descriptive notes and memos about the phenomena observed in the experiments were performed, which were then subjected to analysis with the purpose of finding patterns of behavior that might point to the use of the exercises performed on the basis of their initial objective, as well as to identify the systematic incidence of causes and effects of declared disabilities such as learning, aptitude, and development difficulties.

In light of Piaget's thinking [3], the interactions and the way that the equilibration processes took place were taken into account, that is, the way the students dealt with the challenges in order to find means to adapt and rebalance, thus improving their knowledge. In line with Piaget's ideas, Keith Swanwick shows, through his spiral, the stages of musical development, associating them with certain age groups [4]. In this context, the observation of musical events on both sides of the spiral provided "clues" that allowed any deficiencies to be minimized, outlining important educational paths to creative development. In the same way, the analysis of improvisations can be guided by the study presented by Kratus, in which the author proposes a systematic approach classifying certain improvisation levels [5]. 
Based on the application of the Grounded Theory, proposed by Glaser and Strauss [6], detailed and extensive surveys of the data were carried out through a microanalysis of content, in both the written questionnaires and the reports presented in audiovisual records. We consider microanalysis according to Schröeder [7], as an examination of individual words, sentences, or paragraphs. It is a focused procedure that forces researchers to examine specific information data, not only descriptively but above all analytically, making comparisons on the properties and dimensions level, thus allowing the analyst to disconstruct data and rebuild it in order to form an interpretive scheme.

The set of questions the participants responded in the lab relates to the four basic topics: (a) mutual integration: it ia topic through which we seek information on how each participant experienced the activity; (b) Volitions: collecting informations about decisions: if they desired to do something they were nor able to do, or how they decided to position theirselves in the group; (c) Critical analysis: evaluation of the exercise itself and their own performance when realizing it; and (d) aesthetic aspect and applicability: If the students conceive a way to apply the activities performed in the laboratory, but within their own personal aesthetic music.

Through the interpretative analysis of their reports, both in questions related to these four main topics as in other emerging issues, we got key ideas that originated concepts belonging to categories characterized by specific properties. From the data analysis, there emerged some categories related to each other, where through axial coding it was possible to observe complex elements involved in music making. The Table 1, adapted from its authors [8], presents suggested connectors adopted in Figures 5 to 9 (based on the Grounded Theory), which show the relationships found between the categories and subcategories:

Table 1: Connectors

\begin{tabular}{|c|c|}
\hline Label & Description \\
\hline Is a & $\begin{array}{c}\text { The source-code is a } \\
\text { type or form of } \\
\text { destination-code. }\end{array}$ \\
\hline Is cause of & $\begin{array}{c}\text { The source-code } \\
\text { causes the occurrence } \\
\text { of destination-code. }\end{array}$ \\
\hline Is associated with & $\begin{array}{c}\text { The source-code is } \\
\text { associated with } \\
\text { destination-code }\end{array}$ \\
\hline
\end{tabular}

\begin{tabular}{|c|c|}
\hline Is part of & $\begin{array}{c}\text { The source-code is a } \\
\text { part that, together with } \\
\text { other parts, comprises } \\
\text { the destination-code. }\end{array}$ \\
\hline Is an obstacle to & $\begin{array}{c}\text { The source-code is an } \\
\text { obstacle to the } \\
\text { occurrence of } \\
\text { destination-code. }\end{array}$ \\
\hline
\end{tabular}

\section{First Results}

In order to identify problems that happened in creative activities and practises that occured in music education, we applied a qualitative research metodology that uses statements, answers to questionaries and spontaneous manifestations of students after musical improvisational activities in groups, each of them happening according to various stimuli or proposed challenges. Data collection occurred according to Grounded Theory procedures [6], identifying, organizing and analysing the occurence of "codes" consisting of ideas, contexts and situations indentified in the statements. Analysis also considered the recurrence codes on different occasions, allowing one to infer correlations between them as well as structuring them into categories. Categories represent the common elements and features included in a generic concept of behavior.

\subsection{Emerging Categories}

As shown in Figure 4, the selected categories represent patterns of recurring situations observed in the laboratory sessions of this research, and are called: conservatism, previous knowledge, invention and equilibration.

The conservatism category (Figure $4-$ a) includes several patterns of dimensional variation along its properties. It appears where it is possible to identify occurrence of conservative teaching practices (the traditional model), which create obstacles in musical practice that end up by damaging the education of individuals on their way to achieving full and natural music making and the understanding of music as a reality encompassing all of its true complexity (simplistic reduction). Students who are coming from this context have difficulty in dealing with unexpected situations, since they are used to reacting only through acquired habits. In situations that require unusual and innovative interventions and solutions, the employment of these habits does not show satisfactory results.

However, it was observed that, as the musicians are able to listen, think, and react as they play and create, they begin to have sufficient tools and skills to find appropriate solutions. It is important for the 
teacher's attention to be deep and sensitive enough to realize, through the students' reactions, what their real needs are, as well as the emotional stimulus, a determining factor in musical motivation.

It is possible to observe how traditional model practises can, sometimes, be inflexible in the face of specific educational needs. Among other things it causes: persistent priority in reading, ignoring critical listening; a strong educational trend to aply knowledge involving declarative memory rather than constructive procedural learning. In this context, the strategy is for music to be assimilated and rationally understood first, before going into artistic practice. The content covered is then practically detached from listening and creation and is focused exclusively on the learning of rules and technical procedures.

(a)

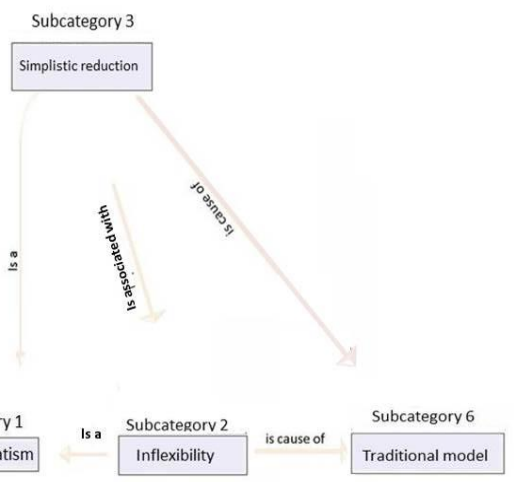

(b)

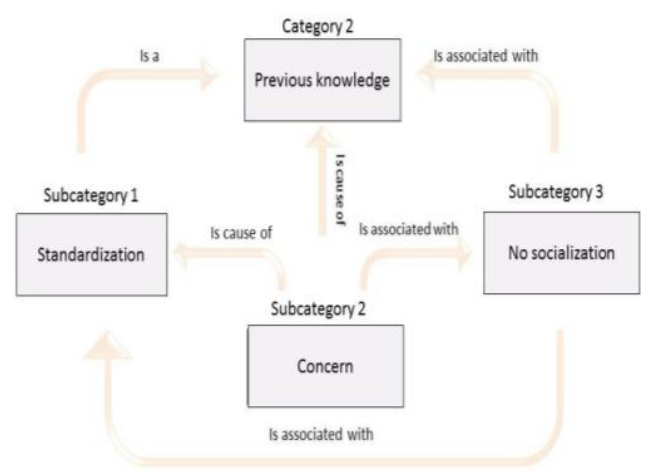

(c)

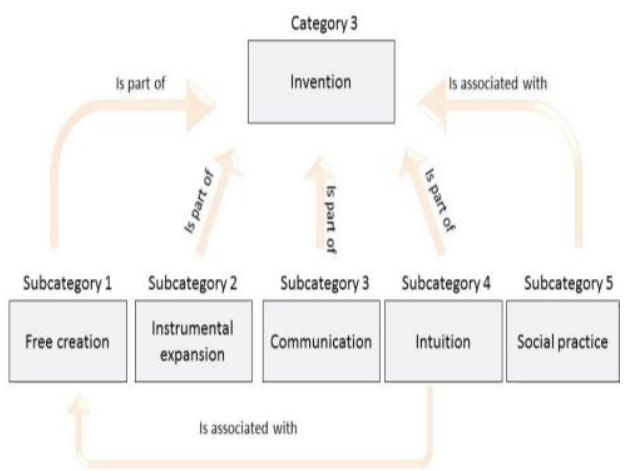

(d)

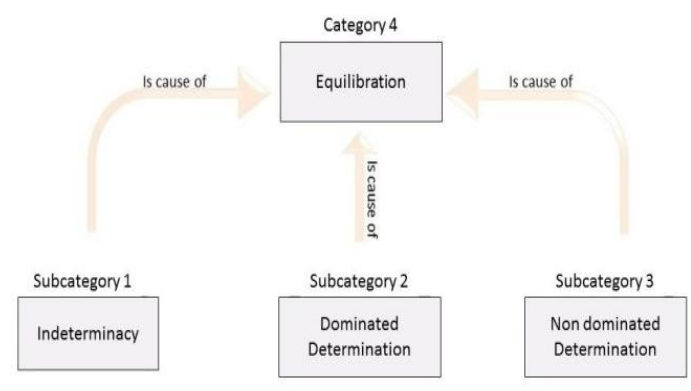

Figure 4: Categories 1 to 4 - (a) category 1; (b) category 2; (c) category 3 and (d) category 4

Another effect resulting from the emphasis on reading is the decontextualization of the musical phenomenon, that is, the student cannot experience music beyond the systematic action of reading notes, since there is no appreciation of listening or critical analysis of what is being produced by he (or she) and his or her partners. Figure 3, shows the relationships between this category and its subcategories:

In the previous knowledge category (Figure $4-\mathrm{b}$ ) three subcategories related to each other were observed: standardization, concern, and no socialization.

Standardization - refers to previous knowledge requirement of specific musical models; Concern - is caused by lack of knowledge of the standards, thus damaging the fluency of his or her performance and causing creative block; No socialization - refers to the exclusion of student participation in musical activities, requiring prerequisites they do not master, thus damaging their integration within the group. Within this context, it was observed in this laboratory, that the requirement of previous knowledge when it comes to performing any musical activity is a result of their traditional learning process that imposes prerequisites to creation (improvised or not). 
The invention category (Figure 4 - c) shows how students realized that being together as they perform the same action generates something exciting for music practice. Their educational background adds: free creation, instrumental expansion, communication, intuition, and social practice, subcategories that can encourage participants to make art:

Free creation - enables free expression, depending on the knowledge available at the moment. It does not require previous knowledge of practical or theoretical nature, or idiomatic music standards. It is a friendly practice, both liberating and exhilarating to the participants, increasing their confidence and enganging them in a pleasurable activity.

Instrumental expansion - refers to the search of technical means, beyond the traditional instrument resources, in order to work in a creative activity. Usually these unconventional techniques are called extended instrumental techniques or expanded instrumental techniques. Additionally, the musical use of extramusical utensils can also be attempted.

Communication - refers to the creative efforts of students to find ways of expressing themselves by using an unusual material or something that causes initial estrangement to them. It occurs in challenging situations in which they are forced to find a common vocabulary and develop it in a discursive way so as to establish a fluent dialogue.

Intuition - an essential element of inventive activities must be in constant balance with rationality and in a synergistic relationship with it. This subcategory highlights the students' learning and how much they loosen up or retrain themselves on account of critical listening during the performance.

Musical development achieved through group practice was a universal agreement in every testimony taken in this study. All of them emphasized the fact that playing together in group developed musical aspects in them that would not be possible in their individual practice. Therefore, social practice was considered a stimulating way of learning music:

In equilibration processes (Figure $4-\mathrm{d}$ ), the subjects, when interacting with new situations, must sometimes readjust schemes. It allows a process of assimilation and accommodation, resulting in new acquired knowledge. Equilibration, schemes, assimilation and accommodation refer to the knowledge building model proposed by Jean Piaget. The time to reach the adjustment varies according to individuals and situations:

In our activities, the equilibration process occured in three situations: indeterminacy, dominated determination, non dominated determination. (a) Situations of indeterminacy were characterized by creations without any pre-established plan; (b) Situations of dominated determination, the students were asked to perform something they knew and therefore was under control; (c) In situations of non dominated determination, the students were asked to perform something for which they were supposedly unprepared or did not know.

In situations of indeterminacy, after a brief initial discomfort, there is the emergence of elements that are quickly shared and understood by the students that end up by getting together and forming a musical idea that goes on to be developed by the group.

In situations of dominated determination the students had knowledge of the musical material to be used and the instrumental techniques involved, and consequently, they had, at first, no difficulties in carrying it out. In these situations, the students started the activites with a lot of confidence and high expectation. However, it was observed that their concern and disappointment at the end of each session was ever harder.

In situations of non dominated determination, where the students should perform something supposedly new or not dominated, despite of the risk, they rise to the ocasion trying to come to terms with it.

In this study group, the occurrence of indicators corresponding to conservatism and previous knowledge were observed, making it possible to stablish a relationship between these two categories and the performance obstacles found by students in the invention category. The latter, in turn, because it encourages students to excell creatively and technically, puts them into somewhat unexpected situations they were forced to solve, thus callilng for equilibration in the process. Figure 5, shows the relationship among the categories previously discussed:

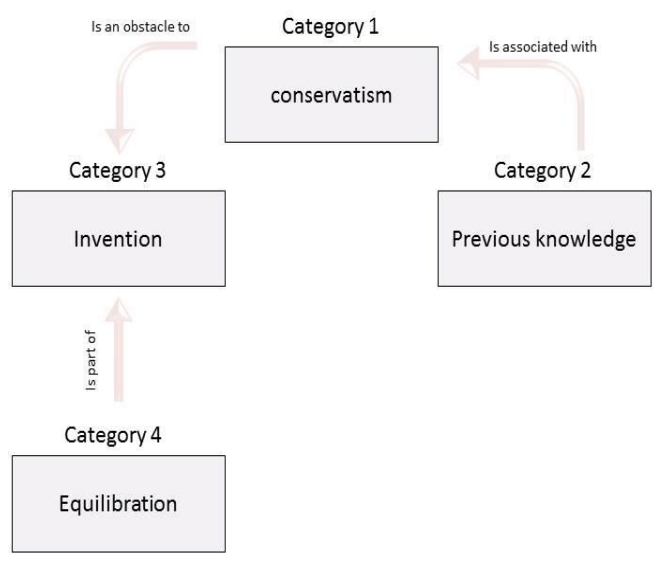

Figure 5: Relationship among categories 


\section{Discussion}

What is the influence of the emerging categories in the creative environment of this study group? Considering that for Edgar Morin [9] all phenomena must be analysed in his entire complexity, since all cognitive events require the conjuction of energy, electrical, chemical, physiological, brain, existential, psychological, cultural, linguistic, logical, ideal, individual, collective, personal, transpersonal, and impersonal interconnected processes, when observing music activities we have a complex phenomenon (in an interdisciplinary and transdisciplinary sense). To ignore this fact is to reduce it to a simplicity level capable of excluding the relationships directly involved in music making. Beliefs, musical influences, psychological state etc., are elements directly and indirectly involved in a simple musical idea developed in a creative activity.

In our laboratory activities, for example, it was observed that certain beliefs involving category 2 (previous knowledge) related to standardization and no socialization damaged the development of several musical creations. Some participants had difficulties related to receptive and productive skills during activities proposed through the reference model, because, according to their reports, they were thinking of standardizations learned in previous studies, or because of concerns related to theoretical and instrumental-technical knowledge. When they realized the possibility of intuitive and inventive creation, free from the demands and requirements of traditional practice, their volitional acts expanded, potentializing their creations and making the activities more pleasurable.

By analyzing the participants' reports, it was noted that certain beliefs related to conservatism category may hinder the creative aspect, itself related to invention category. The conservative practices, often associated with systematic and inflexible actions, create obstacles to inventiveness, since the latter forces participants to resolve unexpected situations during performances. Once participants interact with these challenges, new schemes are constantly constructed, requiring a certain time to be understood and to realize new alternatives and techniques for their musical achievements (equilibration category).

\section{Conclusion}

The categories highlighted in this paper Conservadorism - Previous Knowledge-Invention Equilibration introduced the first indicators to establish relationships among the elements that contribute to, or hinder, music learning through creative art making.

Since the experimental work presented here involved risks, mistakes and successes, for its own nature, we chose to highlight the downside first. In some exercises, we realized that what we requested was beyond the participants' understanding. In this case, the sequence of exercises was immediately reformulated to fit the group; so we asked participants to freely improvise first. The technical resources for each one of the exercices were shown and explained after each improvisation, so the students could become aware of what they did intuitively in their performances. We noticed that knowledge elucidated a posteriori, after the empirical situation was experienced, contributed more effectively for a more concrete learning, since participants were able to relate their actions to the concepts explained.

On the upside: (a) when the participating students completed the activities they were extremely motivated to continue in the folowing semester, meaning that the methods and processes involved, from the musical pedagogy perspective were successful; (b) the students were surprised by the fact that they were playing musical sequences using resources they thought they were uncapable of, meaning that the practices allowed them to be resourceful, capable of outdoing themselves creatively.

The next laboratory sessions will contemplate the application and classification of new creative activities, choose a core category and proceed to theoretical sampling, trying to see whether the provisional hypotheses are confirmed or change, observing the potential codes extracted from the obtained data, and finally, seeking theoretical saturation, that is, stabilization of the trends identified, which will rightly take us to the development of a substantive theory.

\section{Acknowledgements}

We greatly thank Prof. Dr. Manuel Falleiros, currently responsible for the Free School of Music from State University of Campinas (Unicamp), for providing the place and musical instruments. Thanks to São Paulo Research Foundation, by subsidizing this research, enabling its development, publication and dissemination.

\section{References}

[1] Nazario, L.C. and Mannis, J.A. (2014) 'Entre Explorações e Invenções: Vislumbrando um Modelo Referencial para o Desenvolvimento Criativo em Ambientes de Ensino Coletivo', Revista da ABEM, Londrina, pp. 65-76.

[2] Mannis, J.A. (2014) 'Processos cognitivos de percepção, análise e síntese atuando no processo criativo', in proceedings of the Encontro Nacional de Compositores - EnCom, 2., Londrina, pp. 198-225 
[3] Piaget, J. (1999) Seis Estudos de Psicologia. Editora Forense, São Paulo, 1999.

[4] Swanwick, K. (1988) Music, Mind and Education. Routledg, London, 1988.

[5] Kratus, J. (1991) 'Growing with Improvisation', Music Educators Journal. v. 88, n.4, pp. 36-40.

[6] Glaser, B.G. and Strauss, A.L. (1967) The Discovery of Grounded Theory: Strategies for Qualitative Research. Aldine de Gruyter, New York.

[7] Schröeder, C.S. (2009) Educação a Distância e Mudança Organizacional na Escola de Administração da UFRGS: Uma Teoria Substantiva. Tese de doutorado, UFRGS, Porto Alegre.

[8] Conte, T.; Cabral, R. and Travassos, G.H. (2009) 'Aplicando a Grounded Theory na Análise Qualitativa de um Estudo de Observação em Engenharia de Software: Um relato de Experiência', V Workshop: Um Olhar Sociotécnico Sobre a Engenharia de Software - WOSES. Ouro Preto, pp. 26-37.

[9] Morin, E. (1997) La Méthode: La Nature de la Nature. Le Seuil, Nouvelle edition, Paris, 1977. 